\title{
California teachers support the Nutrition Competencies - new nutrition instruction guidelines
}

\author{
by Nadine Kirkpatrick, Marilyn Briggs \\ and Sheri Zidenberg-Cherr
}

Our research group reviewed, updated and field-tested "Nutrition Competencies for California's Children, Pre-Kindergarten through Grade 12," a document that provides comprehensive and sequential nutrition goals for students. The review process included: (1) comparative analysis with state and national nutrition and health documents; (2) professional input by UC nutrition and education faculty and California Department of Education nutrition staff; (3) review by national, state and local experts in nutrition, education and food service; and (4) field review by and a survey of California public school teachers. The teachers that we surveyed overwhelmingly agreed that the final $\mathrm{Nu}$ trition Competencies document was age- and academically appropriate for students in their grade levels. More than $81 \%$ found the Nutrition Competencies document well-structured and user-friendly. The teachers supported its inclusion in the school curriculum, and requested additional support materials such as lesson plans in order to incorporate nutrition lessons into the core subject areas.

$\mathrm{O}$ ver the past two decades, the prevalence of overweight children (ages 6 to 11) in the United States more than doubled (DHS 2004; CDC 2005). Among adolescents (ages 12 to 19), the prevalence more than tripled from 5\% in 1980 to $16 \%$ in 2002. One in three children and one in four adolescents are either overweight or at risk of becoming overweight (DHS 2004). In California, more than a quarter of K-12 students are overweight and nearly two-fifths are

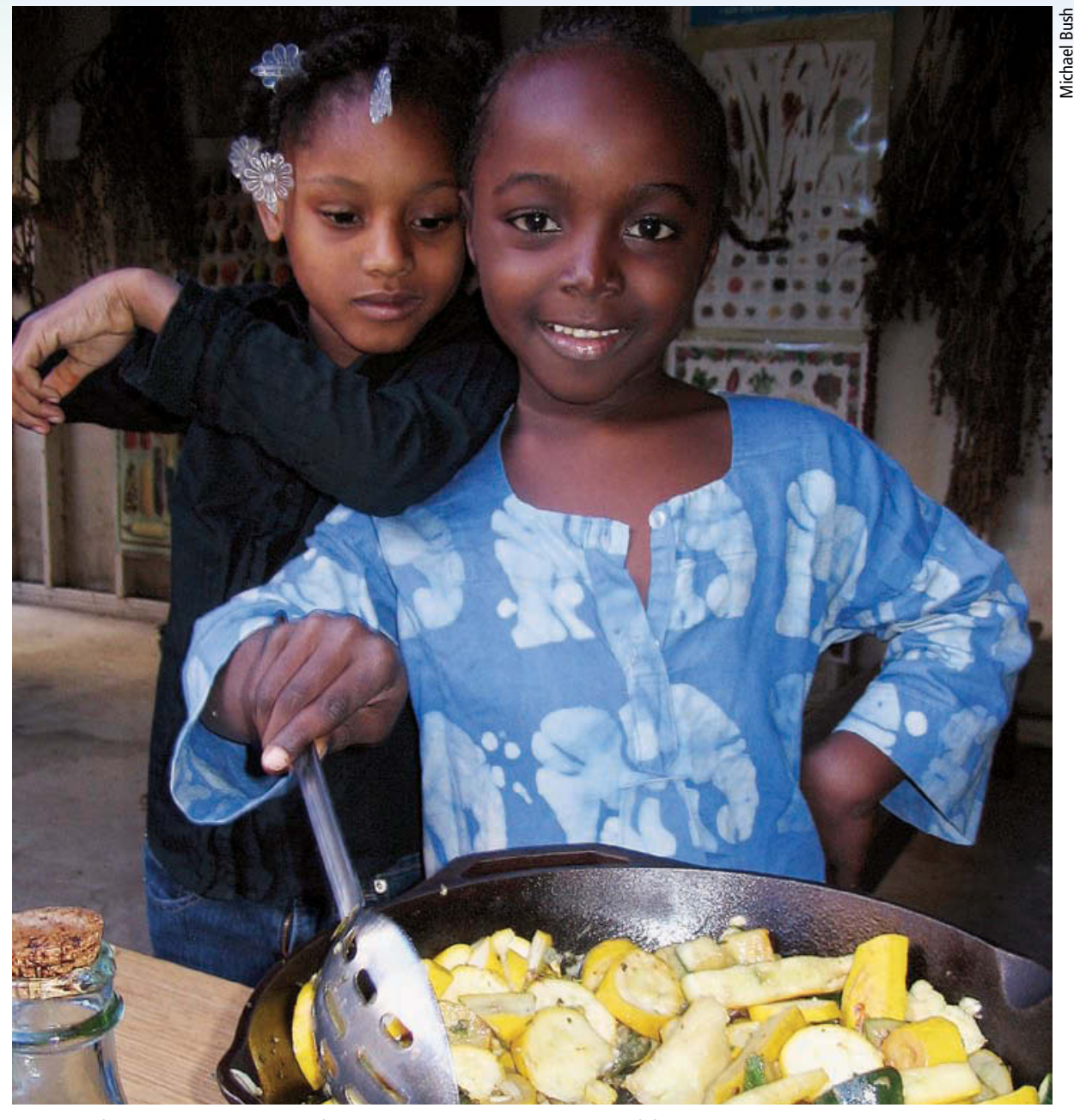

The California Department of Education is in the process of finalizing new guidelines - called the Nutrition Competencies - for educating school-age children about healthy eating and nutrition. In a supervised classroom activity at John Muir Elementary School in Berkeley, 2nd graders Francine and Maraya stir freshly harvested fall vegetables.

considered unfit. Among the affected students, black and Latino youths face higher rates of overweight and lower levels of fitness than white and Asian youths (DHS 2004).

The increase in overweight and related health problems - such as type II diabetes, high blood pressure, high cholesterol and orthopedic problems observed in children over the last two decades supports the need for schoolbased nutrition education. Specifically, it has become increasingly clear that there is a need to provide children with the knowledge and tools to choose a healthy diet and lifestyle.

Comprehensive, school-based nutrition education programs could help to decrease the incidence of overweight and obesity, as well as related chronic diseases such as diabetes and heart disease among Americans (Hoelscher et al. 2002; Anonymous 1997; Olson et al. 1993; Mackie and Oickle 1997). Children are at lower risk of developing such chronic diseases later in life when they are exposed early to nutrition education, including how to cope with stress and the benefits of a balanced diet, regular exercise and not smoking (PerezRodrigo and Aranceta 2001).

School is an ideal environment for implementing nutrition education in a systematic and efficient manner, not only for students but also for teachers, food service and other school staff, parents and community members (Lavin et al. 1992; Nicklas et al. 1997; Briggs et al. 


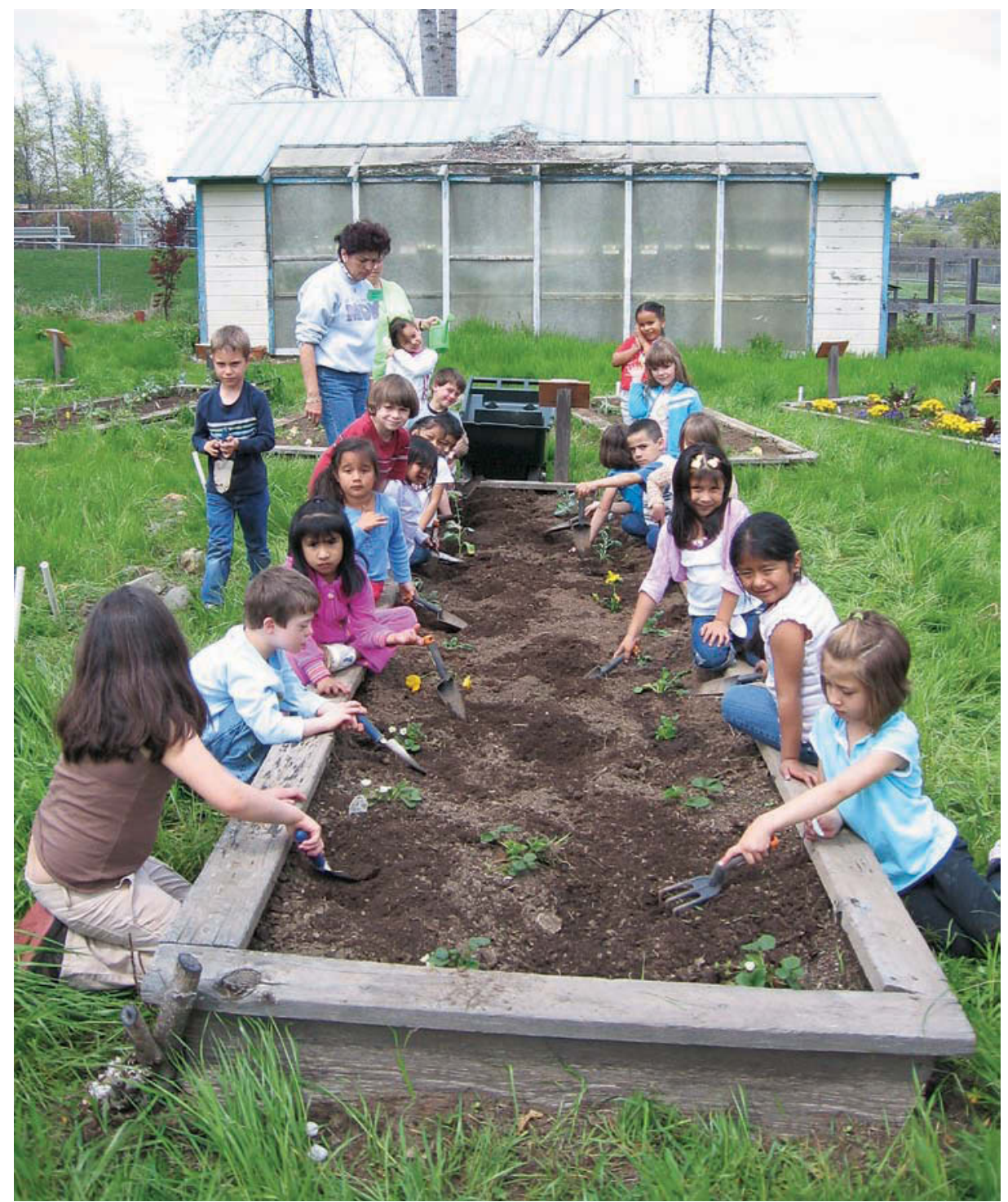

The Nutrition Competencies incorporate farm-to-fork nutrition-education strategies for all grade levels (K-12). At Rock Creek Elementary School in Auburn, kindergarten students tend their garden.

2003; Perez-Rodrigo and Aranceta 2001; Summerfield 1995; Sunseri et al. 1984). Lavin et al. (1992) stated that "schools are society's vehicle for providing young people with the tools for successful adulthood." Having the knowledge and ability to make healthful dietary and lifestyle decisions should be prominent in such a "toolbox."

\section{School wellness policies}

At the national level, the importance of comprehensive, school-based nutrition education programs (Stang and Bayerl 2003) has been exemplified by the Child Nutrition and Special Supplemental Nutrition Program for Women, Infants, and Children (WIC) Reauthorization Act of 2004 (Pilant and ADA 2006). This law requires that every school district participating in the national school lunch or school breakfast programs develop a local wellness policy by the beginning of the 2006-2007 school year. These policies must: (1) include nutrition guidelines for all foods sold on school campuses throughout the school day; (2) include goals for nutrition education, physical activity and other school-based activities that are designed to promote student wellness; (3) establish a plan for implementation of the policy, including designating one or more persons within the local educational agency or at each school to be responsible for compliance; and (4) be developed by parents, students,

\section{Glossary}

Bloom's taxonomy: A taxonomy used specifically in education, particularly in creating standards and learning goals. It categorizes the stages of learning: knowledge, comprehension, application, analysis, synthesis and evaluation.

Competency:Acquiring knowledgeabout, as well as learning skills and becoming proficient in a certain area - in this case, nutrition.

Content standard: Adopted by the California State Board of Education to define what students are expected to know about various school subject areas at each grade level.

Overweight: Children with a body mass index $\left(\mathrm{BMI}=\mathrm{kg} / \mathrm{m}^{2}\right)$ at or above the 95 th percentile of a sex-specific BMI growth chart (DHS 2004). (The Centers for Disease Control and Prevention avoids labeling children as "obese.")

Self-efficacy: The belief that you are competent in what you are doing. Teachers must feel that they have a grasp on the subject material in order to be comfortable teachingit.Self-efficacy can beboosted through short, regular workshops and meetings with other teachers trying to integrate nutrition into the school curriculum.

Unfit:Students who are not able to meet the minimum performance requirements in the following six areas of California physical fitness testing: aerobic capacity, body composition, abdominal strength, upper-body strength, trunk strength and flexibility.

food service staff, the school board, school administrators and the public.

In preparing these new wellness policies, districts throughout California must consider what to base them on and which goals for nutrition education to address. Although the California State Board of Education has adopted content standards for core subject areas such as English-language arts, mathematics, history-social science and science, no such content standards exist for nutrition (CDE 1997a, 1997b, 1998b, 1998c).

\section{The Nutrition Competencies}

Because there are no state nutrition standards to fill this gap, our major objective was to produce the "Nutrition Competencies for California's Children, 


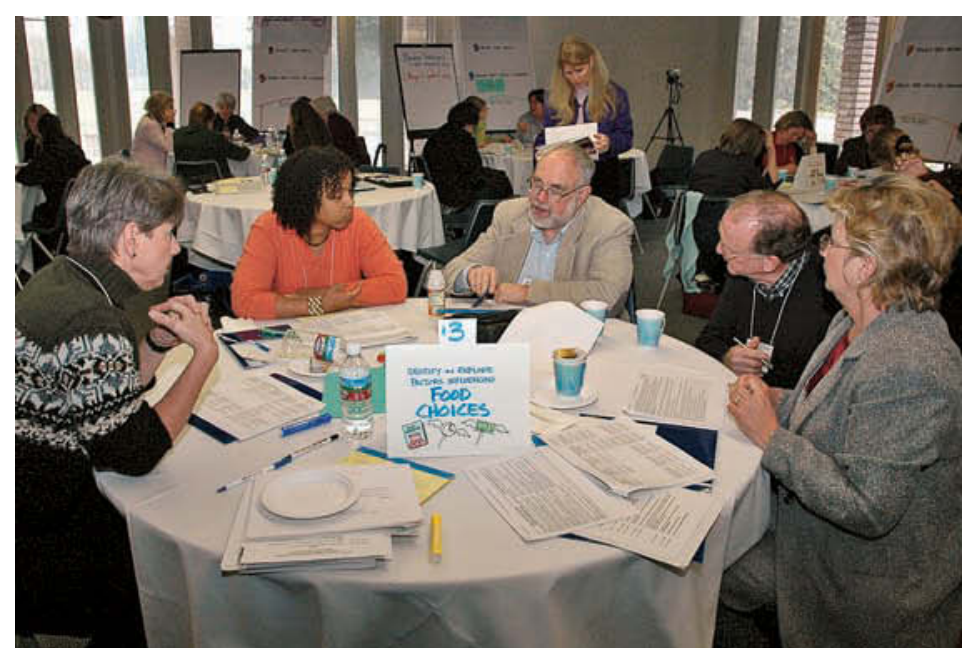

In January 2005, a broad range of stakeholders met in Davis to evaluate a new draft of the Nutrition Competencies document. A small group reviewed the third competency, on food choices.

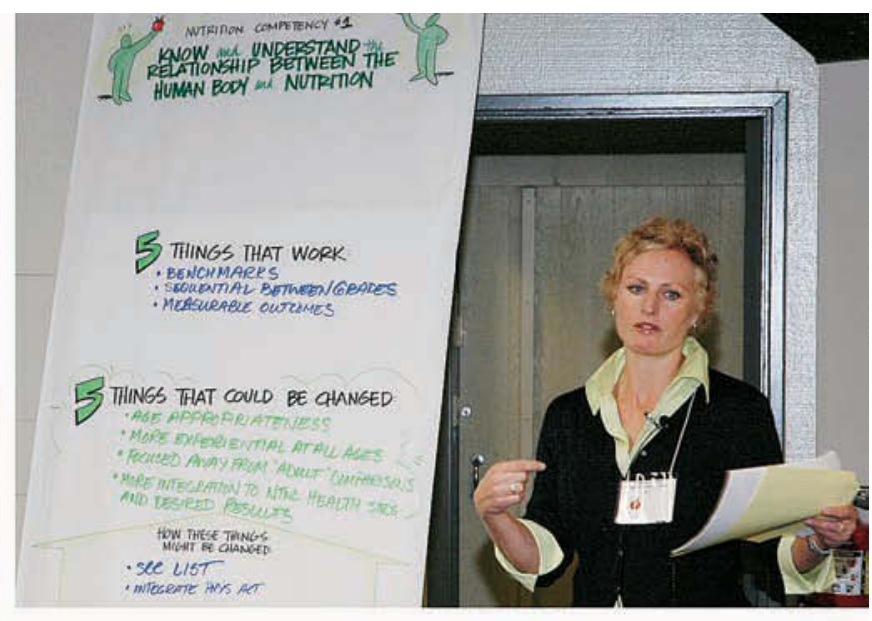

The seven competencies include understanding nutrition recommendations, identifying where foods come from, and handling and preparing food safely. Above, Jamie Buffington, nutrition education chair of the Davis Farm-to-School Connection.

\section{Nutrition Competencies for California's Children, Pre-Kindergarten through Grade 12}

I. Know and understand the relationship between the human body and nutrition.

II. Know current nutrition recommendations and how to apply them.

III. Identify and explore factors influencing food choices.

IV. Identify foods that come from particular regions and understand the factors (local, regional, statewide, national and global) that influence food availability, production and consumption.

V. Demonstrate proper food handling and storage to maximize the nutritional quality of food and personal hygiene to prevent foodborne illness.

VI. Identify valid nutrition information, and advocate for policy.

VII. Identify the variety of foodrelated careers.
Pre-Kindergarten through Grade 12" document, to provide comprehensive and sequential nutrition goals for students. Standards for nutrition education in California schools were first developed as part of the California Department of Education's (CDE) "Choose Well Be Well" documents (CDE 1982a, 1982b; CDE 1984a, 1984b). Based on the minimum proficiencies for nutrition in these documents, the CDE Nutrition Services Division created an initial draft of the Nutrition Competencies document (CDE 2001). Teachers, curriculum specialists, child nutrition program and food service professionals, and nutrition education specialists contributed to this process. The 10 competencies in the $2001 \mathrm{draft}$ version included understanding and applying the Food Guide Pyramid, demonstrating safe food handling and personal hygiene, identifying the factors influencing food intake, explaining nutritional needs and how to access scientifically valid nutrition information, and maintaining a healthy body and positive body image.

Our research group developed and implemented a sequential review process to align the draft Nutrition Competencies document with state and national nutrition and health documents; California content standards for science, history-social science, English-language arts, mathematics and physical education (CDE 2005); and expectations of the "Health Framework for California Public Schools" (CDE 2003). The California
State Board of Education adopted the Health Framework in 2002; it provides a framework for K-12 health education with a focus on safety, violence and other health topics. It is not required in schools, but has played a role in creating California's new mandated "Health Education Content Standards" for schools, expected to be available in 2007. Since nutrition is also in the Health Education Standards, it was important to ensure that the revised Nutrition Competencies emphasized similar nutrition learning goals.

\section{Updating and field-testing}

The purpose of this paper is to describe the development of the updated Nutrition Competencies document and how fieldtesting was used to fine-tune the competencies. Another goal was to determine the overall acceptance of the Nutrition Competencies document among participating California public school teachers. We followed a six-part process to review the Nutrition Competencies.

(1) Comparative analysis. Comparative analysis was conducted to review and analyze related guidelines and standards, including the original 2001 CDE Nutrition Competencies document, in order to develop a new Nutrition Competencies document containing appropriate gradelevel expectations and key nutrition topics compliant with these documents (JCNHES 1995; CCSSO 1998; CDE 1998a). Grade-level expectations are "statement(s) that define what all students should know and be able to do at the end of a given grade level"' (LDE 2004). 
The major outcome of the comparative analysis was that the Nutrition Competencies were narrowed down from 10 to seven "competencies" (see box). The first step in streamlining the competencies was to code each of the original 10 competencies according to thematic concepts. The common themes noted included: dietary guidelines, serving sizes, nutrient types and functions, making healthy food choices, proper food handling, assessing nutritional needs, finding valid nutrition information and food-related careers. In addition, we added themes to the updated Nutrition Competencies, such as human physiology, nutritional needs at different life stages, developing decision-making skills and nutritional supplements.

(2) Linkage to state core-subject standards. The Nutrition Competencies document was also expanded to identify links between grade-level expectations and standards adopted by the State Board of Education for physical education and the core subjects of English-language arts, mathematics, history-social science and science.

(3) Professional input. The updated Nutrition Competencies document was then sent out for review to UC nutrition and education faculty, and CDE nutrition staff. As a result, individual gradelevel expectations were reworded to be more specific, some were moved to different subheadings or competencies, and the order of the seven competencies was modified. Among the themes added to the document were: emphasizing healthy foods, defining foodborne illness and understanding how foodborne illnesses are contracted.

(4) Expert panel. Next, we facilitated a review of the revised document by a panel of expert stakeholders. This panel consisted of 50 professionals including nutrition and education faculty, UC Cooperative Extension advisors and additional agriculture representatives, public school and pre-kindergarten teachers, principals, health and education government agency staff, and food service representatives.

As a result of the expert panel review, additional changes were made to the Nutrition Competencies document. The panel members encouraged linking the document to the expectations of the
"Health Framework for California Public Schools: Kindergarten Through Grade Twelve" (CDE 2003), as well as to the academic California content standards for the core subjects and physical education. The language of the grade-level expectations was changed to reflect Bloom's Taxonomy, emphasizing the sequential organization of the document. In addition, themes were added such as the relationship between nutrition and physical activity, food handling from farm to table, kitchen safety and the food web (producers, consumers and decomposers).

Following incorporation of comments from the expert panel meeting, members of the CDE Internal Review Team provided further input and appropriate changes were made, resulting in an updated document that was ready for field-testing. The new 14-page Nutrition Competencies document now contained seven competencies, with expectations for each competency in each of five grade clusters: pre-kindergarten/kindergarten, lower elementary school (grades 1 to 3 ), upper elementary school (grades 4 and 5), middle school (grades 6 to 8 ) and high school (grades 9 to 12). (The
Nutrition Competencies includes learning goals for pre-kindergarten, and we surveyed a small sample of pre-K teachers. However, the sample was too small to include in this manuscript, so our survey emphasized kindergarten through grade 12 teachers.)

(5) Teacher survey. The primary goal of administering this survey was to obtain feedback from teachers on the utility of the Nutrition Competencies for classroom instruction. Additional purposes of the survey were to compare teacher responses (1) among different grade levels, (2) from schools with and without a history of nutrition education programs and (3) from low-income and not-low-income schools.

A survey was developed to capture teachers' opinions regarding the updated Nutrition Competencies document in six major subject areas: (1) its perceived value, (2) barriers and limitations to its use in preparing nutrition lessons, (3) scope and sequence, (4) age-appropriateness of the gradecluster expectations, (5) appropriateness of links to the expectations of the "Health Framework for California Public Schools: Kindergarten Through

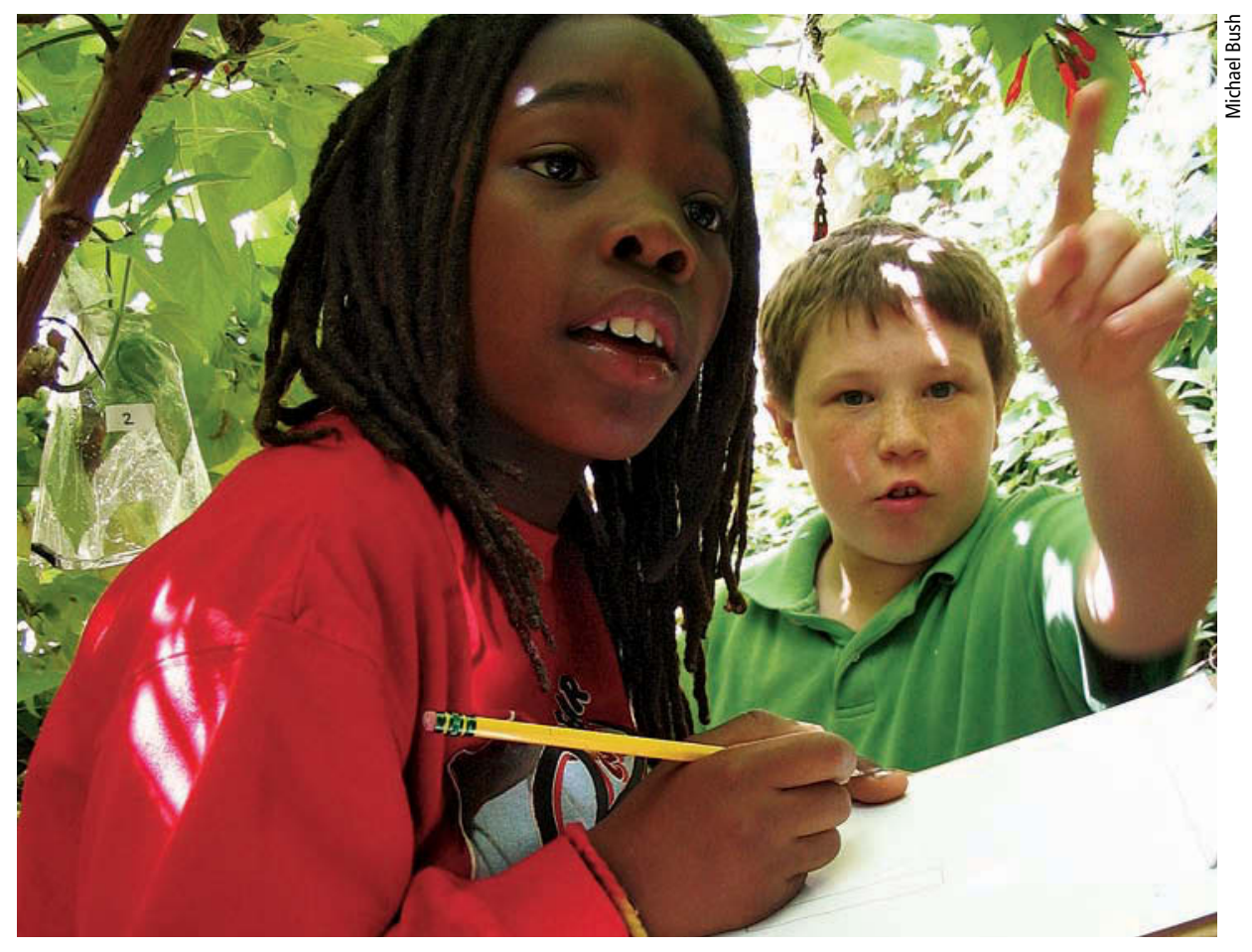

UC nutrition educators plan to use the Nutrition Competencies to develop materials for schoolbased nutrition education and to better integrate nutrition into the school curriculum. Daymon (left) and Jack, 4th graders at John Muir Elementary School in Berkeley, team up for close plant observation under a sage bush. 
Grade Twelve," as well as to California content standards for the core subjects and physical education, and (6) general attitude toward and experience with nutrition education in the classroom.

(6) Field-testing. This survey was pilot-tested on 26 teachers in seven Petaluma City schools to assess its content validity and clarity. The participating schools were later excluded from the California teacher survey sample.

We recruited 250 California public school teachers to participate in the California Teacher Survey. The sample included one teacher per school, and was stratified on multiple levels. First, the sample was stratified by grade-level cluster, with 30 kindergarten, 60 lower elementary, 60 upper elementary, 50 middle school, and 50 high school teachers.

In addition, the kindergarten, 2nd grade and 5 th grade schools were stratified according to whether or not they participated in SHAPE (Shaping Health as Partners in Education), a network of more than 90 California school districts working to improve the health and academic success of California children by providing consistent nutrition messages in child nutrition programs, classrooms and throughout the school environment (CDE 2006). (Elementary school districts mainly use this program, but it is meant for K-12 education.) Finally, the sample was also stratified by income level of the school. An analysis of the association between SHAPE and income on survey response will be discussed elsewhere (manuscript in review).

Middle schools (7th grade) and high schools (10th grade) were stratified by subject areas. Equal numbers of teachers were recruited from the subject areas of English-language arts, health (including both physical education and home economics), history-social science, math and science. In addition, the sample of middle schools and high schools was further stratified by income.

Charter, juvenile hall, continuation and special education schools were eliminated from the sample pool. The schools were numbered and the sample was randomly drawn out of the sample pool. Eligible schools were contacted via phone, and the principals at these schools selected teachers for participation. Overall, 632 schools were contacted; final participation was 250. A total of 217 questionnaires were completed and returned via U.S. mail, resulting in an $86.8 \%$ response rate.

Statistical analysis. The survey data were analyzed with the Statistical

\begin{tabular}{|c|c|c|c|c|}
\hline Competency & Grade-level clustert & Responses (no.) & Mean‡ & Std. dev. \\
\hline \multirow[t]{3}{*}{ I } & ES $(K-5)$ & 136 & $4.3 a$ & 0.8 \\
\hline & MS (6-8) & 39 & $4.7 a$ & 0.7 \\
\hline & HS (9-12) & 42 & $4.2 \mathrm{a}$ & 0.9 \\
\hline \multirow[t]{3}{*}{ II } & ES $(K-5)$ & 135 & $4.0 \mathrm{a}$ & 1.0 \\
\hline & MS (6-8) & 39 & $4.2 \mathrm{ab}$ & 0.9 \\
\hline & HS (9-12) & 41 & $4.4 b$ & 0.9 \\
\hline \multirow[t]{3}{*}{ III } & ES $(K-5)$ & 136 & 4.1a & 0.9 \\
\hline & MS (6-8) & 39 & $4.2 \mathrm{a}$ & 0.7 \\
\hline & HS (9-12) & 41 & $4.3 a$ & 0.9 \\
\hline \multirow[t]{3}{*}{ IV } & ES $(K-5)$ & 132 & $3.2 \mathrm{a}$ & 1.2 \\
\hline & MS (6-8) & 38 & $3.8 b$ & 0.9 \\
\hline & HS (9-12) & 41 & $4.1 b$ & 1.1 \\
\hline \multirow[t]{3}{*}{ V } & ES $(K-5)$ & 136 & $3.7 a$ & 1.1 \\
\hline & MS (6-8) & 39 & $3.6 a$ & 1.1 \\
\hline & HS (9-12) & 41 & $4.0 \mathrm{a}$ & 1.1 \\
\hline \multirow[t]{3}{*}{ VI } & ES $(K-5)$ & 136 & $3.8 a$ & 1.0 \\
\hline & MS (6-8) & 39 & $4.1 \mathrm{a}$ & 0.9 \\
\hline & HS (9-12) & 41 & $4.2 \mathrm{a}$ & 1.0 \\
\hline \multirow[t]{3}{*}{ VII } & ES $(K-5)$ & 136 & $3.6 a$ & 1.4 \\
\hline & MS (6-8) & 38 & $3.7 a$ & 0.9 \\
\hline & HS (9-12) & 40 & $3.9 a$ & 1.2 \\
\hline \multicolumn{5}{|c|}{ Teachers responded on a five-point Likert scale with $1=$ do not agree } \\
\hline \multicolumn{5}{|c|}{ † ES = elementary school; MS = middle school; HS = high school. } \\
\hline \multicolumn{5}{|c|}{$\begin{array}{l}\text { ₹ Within each competency, means followed by same letters do not differ significantly from one } \\
\text { another at the } 0.05 \text { level of significance (Tukey post-hoc test). }\end{array}$} \\
\hline
\end{tabular}

Package for the Social Sciences for Windows (SPSS Inc., ver. 13.0, Chicago, Ill., 2004). Descriptive statistics were calculated for all survey questions. Missing data and "not applicable" responses were excluded from all analyses. Chi-square tests and analysis of variance (ANOVA) were conducted to detect any differences in teacher responses by grade level. A significance level of $P \leq 0.05$ was set a priori. Follow-up tests to the ANOVA analyses were performed using the Tukey post-hoc test at a $5 \%$ procedure-wise error rate. Chi-square tests were adjusted for multiple comparisons using Bonferroni techniques in order to have a $5 \%$ procedure-wise Type I error rate for each dependent variable. Here, for each post-hoc test conducted, $P \leq$ $0.05 / 3=0.0167$ was considered to be statistically significant.

\section{California teacher survey}

Perceived value. The majority of teachers surveyed agreed that the Nutrition Competencies document had value to them as teachers (more than 92\%) and to their students (more than 97\%). All of the kindergarten through 5th-grade (elementary school) teachers agreed that the Nutrition Competencies had value to them, whereas $92.3 \%$ of high school teachers agreed. A chisquare follow-up test, adjusted for multiple comparison, showed that the difference between elementary and high school teachers is significant $(P=0.012)$. This result indicates that elementary school teachers are more willing to embrace a document like the Nutrition Competencies in their curricula, while high school teachers may be hesitant because they are preoccupied with preparing students for testing.

Overall acceptance. A majority of teachers agreed or strongly agreed $(72.9 \%)$ that they would use the Nutrition Competencies to plan nutrition lessons for their students. There were no significant differences among teachers from the different grade clusters.

Age-appropriateness. More than 93\% of teachers said that the Nutrition Competencies document was ageappropriate for the grade level that they teach. There were no significant differences among teachers from the different grade clusters. 
The teachers also rated the ageappropriateness of the seven individual nutrition competencies on a scale ranging from "do not agree" to "strongly agree." When comparing the responses of teachers by the grade cluster in which they teach (elementary, middle or high school), most agreed or strongly agreed that Competency I (more than 83\%) and Competency II (more than 72\%) were appropriate. Significant differences were found in how teachers rated Competency II: more high school teachers $(88 \%)$ agreed or strongly agreed that Competency II was age-appropriate than did teachers from the elementary school grade cluster $(73 \% ; P=0.028)$ (table 1$)$.

The majority of teachers from these three grade clusters agreed or strongly agreed that Competency III (more than $80 \%$ ), Competencies V and VI (more than $60 \%$ ) and Competency VII (more than $58 \%$ ) were age-appropriate. ANOVA with a Tukey post-hoc test showed significant differences in how teachers rated the age-appropriateness of Competency IV: a higher percentage of middle school $(58 \% ; P=0.027)$ and high school $(76 \% ; P=0.001)$ teachers agreed or strongly agreed that Competency IV was age-appropriate than did teachers from the elementary school cluster $(47 \%)$ (table 1).

Scope and sequence. A considerable percentage of teachers in all grade clusters (more than $81 \%$ ) found the Nutrition Competencies document well-structured and user-friendly. Most teachers (more than $81 \%$ ) agreed that the document is sequential within each grade cluster, meaning that the presented concepts build on each other and can be taught in order. This is important when putting together learning goals or standards for any subject area, to keep students on track and build on their previous knowledge. A high percentage of all teachers (more than $89 \%$ ) also agreed that the document's grade-level expectations within each grade cluster were sequentially organized.

\section{Teacher suggestions}

Several teachers provided suggestions for improving the Nutrition Competencies document in the qualitative portion of the survey. Their comments were coded and sorted into categories.

\section{Teachers often mentioned that the rising number of overweight students motivates them to teach nutrition in their classrooms.}

Several teachers had suggestions and concerns regarding lesson plans. Sample lesson plans and curricula, particularly integrated ones, were the most requested items. An integrated lesson plan would connect the learning goals of the Nutrition Competencies with specific California academic core subject standards (that the teachers have to address) and give them a detailed lesson plan that includes possible activities, homework and so on. The other items requested were materials, resources, supplies, teacher training and integrated textbooks.

The challenge of time constraints for integrating nutrition into the school curriculum was commonly mentioned. Many teachers suggested that the Nutrition Competencies be incorporated into what they already teach, due to the lack of time during the regular school day to make nutrition a separate subject.

Some teachers suggested making nutrition an elective class in middle and high school, or incorporating nutrition into health or physical education classes. It was also suggested that nutrition concepts be made a requirement and part of California state testing.

In addition, it was noted that foods available on school campuses should reflect what students learn in class. Finally, teachers had concerns about the potential lack of support regarding nutrition education from administrators. Many did not think administrators would fully support teachers who wanted to integrate nutrition lessons into their classes and curriculum; they thought they would not have sufficient time and monetary support to plan nutrition lessons, which would result in very few teaching materials available to actually put lessons together.

\section{School-based nutrition education}

The teacher survey was the concluding step in the systematic review process and contributed to producing the final updated "Nutrition Competencies for California Children, Pre-Kindergarten through Grade 12." We found that California public school teachers from all grade levels supported the incorporation of the Nutrition Competencies into the school curriculum.

Teachers strongly agreed that there is a need for the Nutrition Competencies and often mentioned that the rising number of overweight students motivates them to teach nutrition in their classrooms. "I think the Nutrition Competencies are well done, and certainly something much needed in society today. I also like the way it is taught all through the school years. The lessons should span 10 weeks or more, week after week, year after year," one teacher explained.

Future directions of research should include conducting focus groups with teachers from all grade levels to improve the links between the Nutrition Competencies document and California content standards for the core subjects and physical education. One teacher wrote: "This provides a wealth of information for students to become more nutritionally aware [and] intelligent. I see teachers being more apt to include this curriculum if it is integrated with their current curriculum/standards-based lessons, which, in kindergarten, was included very well." Another teacher noted: "The best way to make sure that nutrition is being taught is to give single-subject teachers lesson plans that are standardsbased (they already have to teach them) but infused with the nutritional curriculum. Time is so precious most teachers can't/ won't find the time to include nutrition lessons unless you show them how."

The results of this study have implications for the application, implementation and success of the Nutrition Competencies. Teachers need to be provided with appropriate resource materials and training to develop selfefficacy when teaching nutrition in the classroom. The written feedback from teachers participating in the survey also implies that teaching children and young adults about nutrition cannot be the sole responsibility of teachers. School-based nutrition education requires a sequential and comprehensive framework that helps teachers to plan their lessons. In addition, to ensure that schoolwide nutrition policies are 


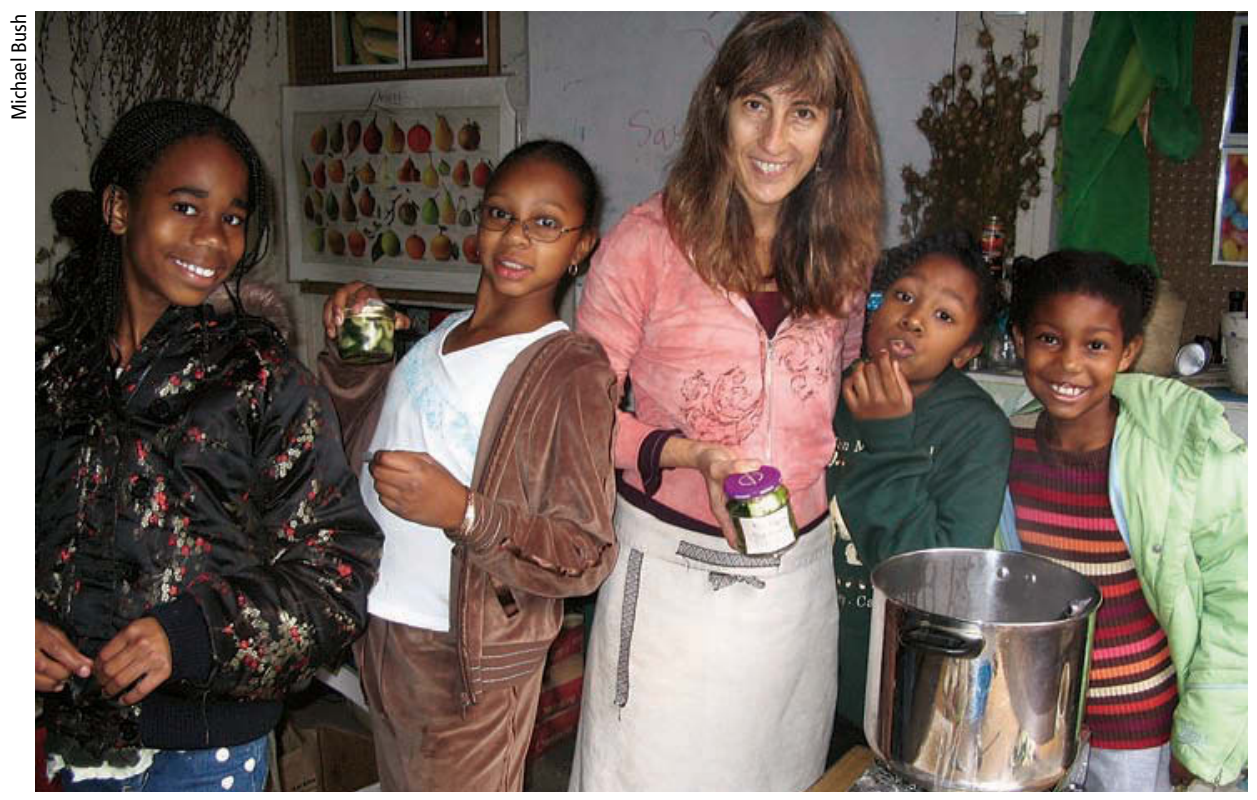

Teachers from across the state were surveyed to assess the final 14-page Nutrition Competencies document, including its perceived value to them and its age-appropriateness for particular grade levels. At John Muir Elementary School in Berkeley, "chef Carrie" made pickles with 4th and 5th graders (left to right) Jalaya, Naomi, Naila and Kayla.

in place, there must be coordination with food service staff, family and other members of the community, as well as school administrators (Auld 1998).

The Nutrition Competencies document has undergone a few more revisions since our research group presented CDE with our "final version"; it is not yet required in schools and will take some time until we see it in the classroom. The UC Davis Department of Nutrition plans to post the Nutrition Competencies to the Internet (http:/ / nutrition.ucdavis.edu) and to use the document as a basis for providing additional school-based nutrition education support. Our survey showed that teachers recognize the need for incorporating nutrition into the school curriculum. As more support materials become available, they will have the resources they need for incorporating nutrition lessons into their daily school curriculum.

N. Kirkpatrick is Adjunct Professor, Department of Family and Consumer Science, Sacramento City College, Sacramento; M. Briggs is Doctoral Student Researcher, and S. Zidenberg-Cherr is Cooperative Extension Specialist, Department of Nutrition, UC Davis. This project was funded in part by the California Department of Education (CDE), Sacramento, and the UC Davis Food Stamp Nutrition Education program. The authors thank Helen Magnuson of the CDE Nutrition Services Division for being our contact with CDE; teachers of the Petaluma School District for evaluating the Nutrition Competencies survey during the pre-test; and all the California public school teachers who took part in the Nutrition Competencies survey. Special appreciation is given to Mark Hudes of UC Berkeley for his statistical assistance. We also thank Trevor Cherr, Stephanie Cozad, Linh Dang, Anna Jones and Joe Kopshever for their tremendous dedication to subject recruitment and data entry.

\section{References}

Anonymous. 1997. Guidelines for school health programs to promote lifelong healthy eating. J School

Auld G, Romaniello C, Heimendinger J, et al. 1998. Outcomes from a school-based nutrition education program using resource teachers and cross-disciplinary models. J Nutr Ed 30(5):268-80.

Briggs M, Safaii S, Beall DL. 2003. Position of the American Dietetic Association, Society for Nutrition Education, and American School Food Service Associaton. Nutrition services: An essential component of comprehensive school health programs. J Am Diet Assoc 103(4):505-14.

[CCSSO] Council of Chief State School Officers. 1998. Health Education Assessment Project et al. Assess ing Health Literacy: Assessment Framework. Santa Cruz, CA: Toucan Ed Pub.

[CDC] Centers for Disease Control and Prevention 2005. Prevalence of Overweight Among Children and www.cdc.gov/nchs/products/pubs/pubd/hestats/ overwght99.htm.

[CDE] California Department of Education. 1982a. Choose Well Be Well: A Curriculum Guide for Preschool and Kindergarten. Sacramento, CA.

CDE. 1982b. Choose Well Be Well: A Curriculum Guide for the Upper Elementary Grades. Sacramento, CA.

CDE. 1984a. Choose Well Be Well: A Curriculum Guide for High School. Sacramento, CA.

CDE. 1984b. Choose Well Be Well: A Curriculum Guide for Junior High School. Sacramento, CA. Health 67(1):9-26. Adolescents: United States, 1999-2002. Hyattsville, MD.
CDE. 1997a. English-Language Arts Content Standards for California Public Schools: Kindergarten Through Grade Twelve. Sacramento, CA. www.cde. ca.gov/be/st/ss/engmain.asp.

CDE. 1997b. Mathematics Content Standards for California Public Schools: Kindergarten Through Grade Twelve. Sacramento, CA. www.cde.ca.gov/be/st/ss/ mthmain.asp.

CDE. 1998a. Challenge Standards for Student Success: Health Education. Sacramento, CA. www.cde. ca.gov/challenge/Contents.html.

CDE. 1998b. History-Social Science Content Standards for California Public Schools: Kindergarten Through Grade Twelve. Sacramento, CA. www.cde. ca.gov/be/st/ss/hstmain.asp.

CDE. 1998c. Science Content Standards for California Public Schools: Kindergarten Through Grade Twelve. Sacramento, CA. www.cde.ca.gov/be/st/ss/scmain.asp.

CDE. 2001. Nutrition Competencies for California's Children, Pre-Kindergarten through Grade 12. Draft. Sacramento, CA. www.cde.ca.gov/ls/nu/he/documents/ nutrcomp.pdf.

CDE. 2003. Health Framework for California Public Schools: Kindergarten Through Grade Twelve. Sacramento, CA. www.cde.ca.gov/re/pn/fd/documents/ health-framework-2003.pdf,

CDE. 2005. Physical Education Model Content Standards for California Public Schools: Kindergarten Through Grade Twelve. Sacramento, CA. www.cde. ca.gov/re/pn/fd/documents/pestandards.pdf.

CDE. 2006. SHAPE California. www.cde.ca.gov/ls/ nu/he/shape.asp.

[DHS] California Department of Health Services. 2004. California Obesity Prevention Initiative. www.dhs. ca.gov/ps/cdic/copi/html/problem.htm.

Hoelscher DM, Evans A, Parcel GS, Kelder SH. 2002. Designing effective nutrition intervention for adolescents. J Am Diet Assoc 102 (suppl 3):S52-63.

[JCNHES] Joint Committee on National Health Education Standards. 1995. National Health Education Standards: Achieving Health Literacy. American Cancer Society, Atlanta, GA. www.aahperd.org/aahe/pdf_files/ standards.pdf.

Lavin AT, Shapiro GR, Weil KS. 1992. Creating an agenda for school-based health promotion: A review of 25 selected reports. J School Health 62(6):212-28.

[LDE] Louisiana Department of Education. 2004. Division of Student Standards \& Assessments Grade-Level Expectations. www.doe.state.la.us/lde/ssa/1819.html.

Mackie JW, Oickle P. 1997. School-based health promotion: The physician as advocate. CMAJ 156(9):1301-5.

Nicklas TA, Johnson CC, Webber LS, Berenson GS. 1997. School-based programs for health-risk reduction. Annal NY Acad Sci 817(1):208-24.

Olson CM. 1995. Position of ADA, SNE, and ASFSA: School-based nutrition programs and services. J Am Diet Assoc 95(3):367-9.

Perez-Rodrigo C, Aranceta J. 2001. School-based nutrition education: Lessons learned and new perspectives. Public Health Nutr 4(1A):131-9.

Pilant VB, [ADA] American Dietetic Association. 2006. Position of the American Dietetic Association: Local Support for Nutrition Integrity in Schools. J Am Diet Assoc 106(1):122-33.

Stang J, Bayerl CT. 2003. Position of the American Dietetic Association: Child and adolescent food and nutrition programs. J Am Diet Assoc 103(7):887-93.

Summerfield LM. 1995. National Standards for School Health Education. www.ericdigests.org/19962/health.html.

Sunseri AJ, Alberti JM, Kent ND, et al. 1984. Ingredients in nutrition education: Family involvement, reading and race. J School Health 54(5):193-6. 